\title{
The Study of Seaworthiness of Universal Rescue Vehicle with Rotary Screw Propeller
}

\author{
M.Y. Sandakov, M.L. Mukhina, A.A. Koshurina, M.S. Krasheninnikov and R.A. Dorofeev \\ 603950, Russia, Nizhny Novgorod, Minina street, 24, NNSTU named after R.E. Alekseev
}

\begin{abstract}
To increase the production of hydrocarbons Russia stepped on the shelf of the Arctic seas. The Arctic, as it is known, is characterized by severe climatic conditions, it can be attributed to the extremely long frosty winter, strong winds, six-month polar nights and ice on the surface of the sea all year round. In these natural conditions exploration and production of oil and gas is carried out. To perform these tasks there are ice-resistant drilling stations of various types operating at a considerable distance from shore bases and from each other.

In the work of drilling rig systems there are risks of emergency situations (fire, release of oil or gas, tipping over of the platform under the influence of external factors, ice compression with the hull damage, a hole in the waterproof casing with subsequent flooding, etc.). For rescue and evacuation of the personnel of the drilling rig from the place of accident in the Arctic we need special rescue vehicle capable of moving both on water and on land.
\end{abstract}

Keywords-component; rotary screw propeller; amphibious vehicles; seaworthiness; theoretical drawing of geometric body; floatability; propulsion; curve of areas of waterplanes; curve of displacement; the arctic

\section{INTRODUCTION}

The amphibious vehicle with rotary-screw propeller can solve the problems of saving people from the dangerous facilities in the Arctic [1]. This universal rescue vehicle (URV) (Figure 1) has excellent performance in off-road conditions: the ability to move through the swampy coast, overcoming obstacles; to move easily on snow and ice; to cross the sea, moving with decent speed on water and even in the broken ice.

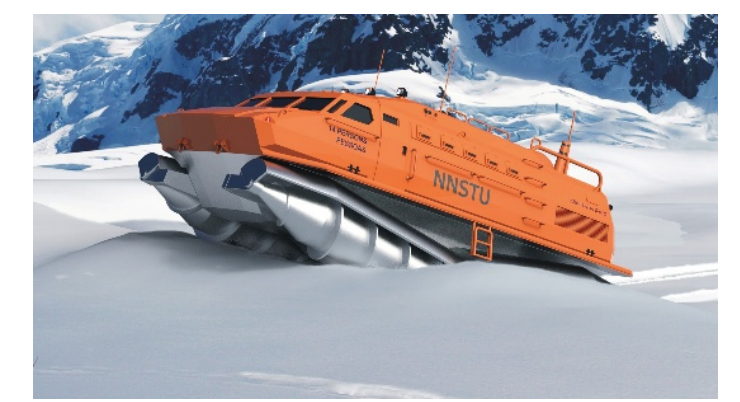

FIGURE I. THE UNIVERSAL RESCUE VEHICLE WITH ROTARY SCREW PROPELLER

One of the main advantages of the amphibious vehicle is stable movement on the water surface [2]. Therefore, the proposed universal vehicle as any floating structure must have seaworthiness. The seaworthiness includes the following abilities:
- to float, in both normal and the damaged conditions with the total load and the crew, having certain embarkation;

- to maintain a state of stable equilibrium under the influence of external forces, both in direct and in an inclined position;

- to float in case of submergence of one or more rotors (screws);

- to have smooth and slow rocking while floating;

- to float in any direction at a certain speed and to keep maximum speed with minimum capacity of the power plant, on both calm and rough surfaces of the water;

- to have a good turning quality under the operation of the steering wheel;

- to preserve rectilinear motion and the smallest deviation from the course at the fixed position of the steering wheel.

All of the above mentioned qualities are identified with seaworthiness of the amphibious vehicle: buoyancy, stability, unsinkability, smooth rocking, propulsion, turning ability and stability.

For studies and calculations to identify and estimate seaworthiness of the universal rescue vehicle we need to create a geometric body with the watertight surface of both submerged and above-water parts and reproduce the shape and dimensions of the vehicle without protruding constructions (brackets, screw rotor blades, drives, frames, reinforcement ribs, etc.). Such body is called the molded body of the floating structure [3] (Figure 2).

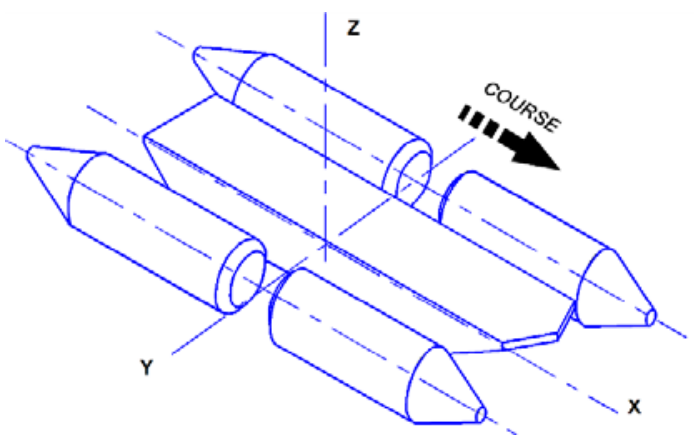

FIGURE II. MOLDED BODY OF THE UNIVERSAL RESCUE VEHICLE

For geometric representation of the configuration of the molded body its surface is displayed in three projections for three mutually perpendicular planes: the center plane, longitudinal vertical plane of geometric surface symmetry, 
plane of the load waterline, passing through the free surface of the calm water when floating with full load (weight), and the plane of the middle-ship frame, dividing the molded body into two parts with equal length: the fore-body and after-body. The molded body of our vehicle is divided into 20 station sections at equal distances of 0.478 meters along the length of the load waterline. The results of the cross sections are shown at the third projection of the orthogonal drawing (body projection). Also, a molded body of the universal rescue vehicle is dissected into 9 waterlines from the main line at equal distances of 0.192 meters. The results of these intersections are plotted on the projection of the load waterline, graphically describing only half of the contours (half-breadth plan projection). The system of cross-sections of the molded body by mutually perpendicular planes together form a line drawing, projections of which are called profile plan, half-breadth plan and body-plan.

Images on the line drawing of the universal rescue vehicle (Figure 3 ) are shown by the projections of profile plan, halfbreadth plan and body-plan. The forward end of the projection is displayed on the right side. The front line of the forward end is called the forward bow. The after-body plan of the universal rescue vehicle is called the transom. The line of transition of the fore-body to the board is called the shoulder. The bottom line of the universal rescue vehicle body is called the keel. The proposed contours (surface shape of the body and rotors) of the universal rescue vehicle are characterized by the stem angle of 29 degrees, which positively affects the motion of the vehicle on waves, in the broken ice, when entering the ice and the shoreline. Sharpening of the fore-body near the construction waterline (CW) is 75 degrees, which has a positive effect on improving the propulsion, stability of the course and icebreaking capability when moving in the broken ice. A part of the transom is inclined 32 degrees to the main line; it allows the vehicle not to push the broken ice when reversing. It also reduces the risk of impact of the body on the ice edge entering the ice from water. When traveling forward overland it allows the vehicle not to touch the obstacles (such as bumps, ridges and ice ridges). On the projection of the body drawing we can see the deadrise of the boat, which is 5 degrees. It allows reducing lateral drift of the universal rescue vehicle without losing the useful volume of the body, when moving on water.

After describing the line drawing of the universal rescue vehicle, we can review the list of its elements:

Maximum length $\mathrm{L}_{\max }=10600 \mathrm{~mm}$

Length between perpendiculars $\mathrm{L}_{\mathrm{CW}}=9560 \mathrm{~mm}$

Breadth $\mathrm{B}_{\max }=5203 \mathrm{~mm}$

Width at the construction waterline $\mathrm{B}=4968 \mathrm{~mm}$

Depth at midship $\mathrm{H}=1830 \mathrm{~mm}$

Draft of the universal rescue vehicle full loaded $\mathrm{T}=960$ $\mathrm{mm}$

Distance between the station section - station spacing $\Delta \mathrm{L}=$ $478 \mathrm{~mm}$

Distance between the waterlines $\Delta \mathrm{T}=192 \mathrm{~mm}$
With the line drawing of the geometric body of the universal rescue vehicle we can investigate and calculate the parameters characterizing the buoyancy and initial stability of the vehicle. The most important in the assessment of the buoyancy is the area curve at the waterline (Figure 4) [4] and the displacement curve of the universal rescue vehicle (Figure 5). [4] These relationships characterize the size of the area and volume of the underwater part of the vehicle, depending on the draft of the universal rescue vehicle on an even keel (horizontally).

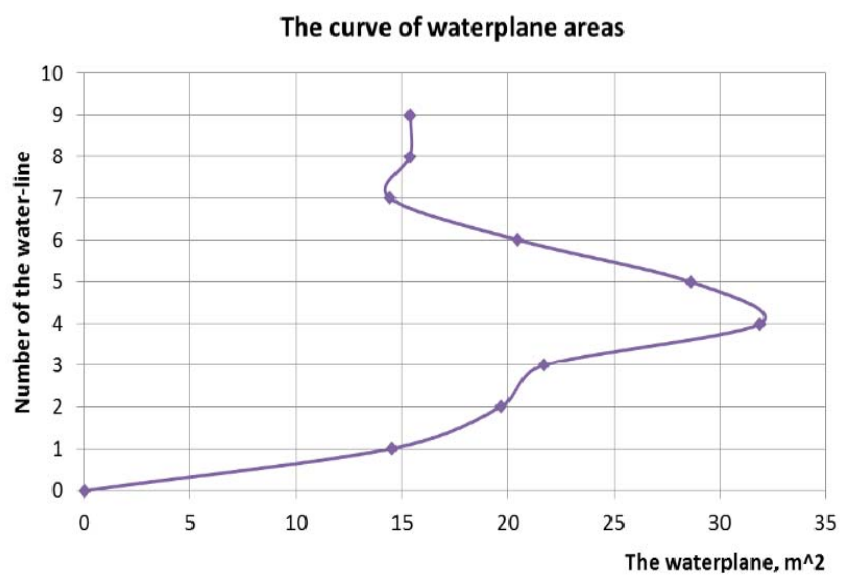

FIGURE IV. AREA CURVE AT THE WATERLINE OF THE UNIVERSAL RESCUE VEHICLE

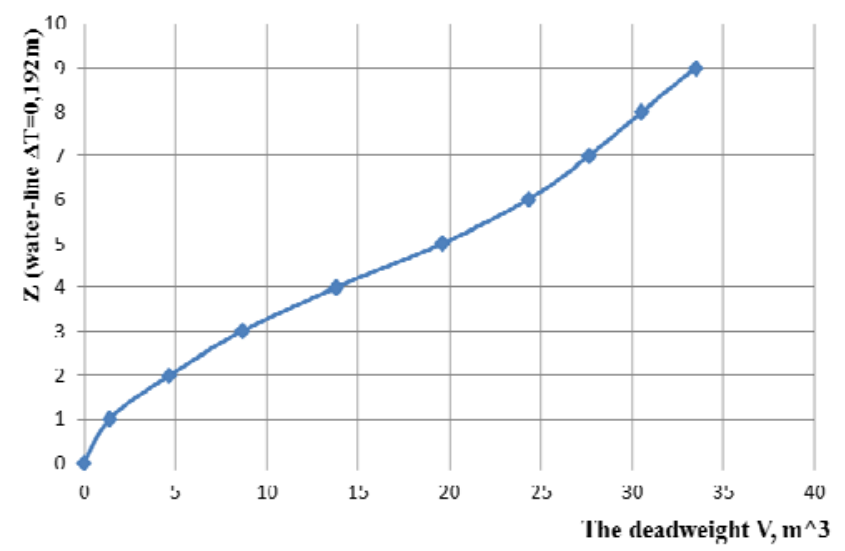

FIGURE V. MOLDED BODY OF THE UNIVERSAL RESCUE VEHICLE

The authors came to studying propulsion of the vehicles with rotary-screw propeller after thorough examination of statistical series of similar vehicles. At first we collected information on the characteristics of the movement of vehicles of this type on water. Selecting the information we paid special attention to such parameters as the speed of movement on water, geometric dimensions of the vehicles, the engine power and the vehicle weight. For classification and evaluation of the data we built the inertial energy dependence of the screw-propelled vehicles when moving on water. This is a graphical dependence of power density of the screwpropelled vehicles on the Froude number (Figure 6).

Specific power is the power-to-weight of the vehicle; it is measured in units $(\mathrm{kWh} / \mathrm{t})$. 
The Froude number is a dimensionless coefficient relating the inertial and gravitational characteristics of a moving object [4] Using this tool we can compare the speed of the objects with different dimensions.

$$
E r=\frac{v}{\sqrt{\Sigma g}}
$$

where: $\mathrm{v}$ - velocity of the vehicle $(\mathrm{m} / \mathrm{s})$; L - the overall length of the vehicle $(\mathrm{m}) ; \mathrm{g}$ - acceleration of gravity $\left(\mathrm{m} / \mathrm{s}^{2}\right)$.

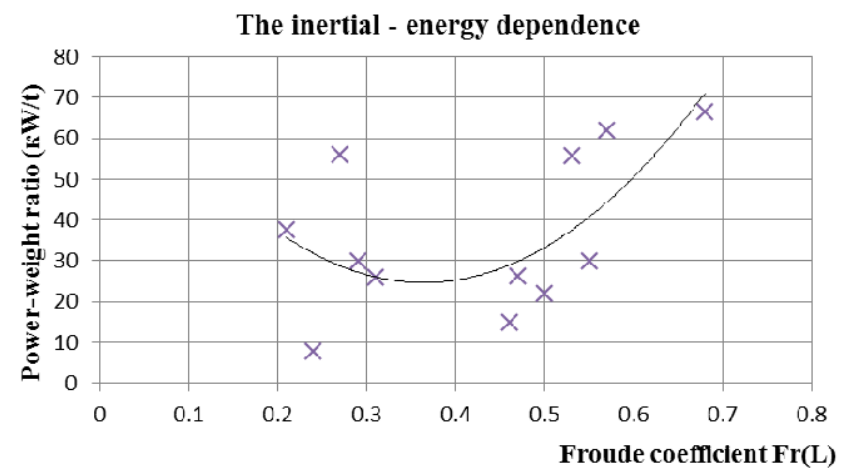

FIGURE VI. DISPLACEMENT CURVE OF THE UNIVERSAL RESCUE VEHICLE

\section{CONCLUSION}

The universal rescue vehicle developed in the NNSTU named after R. E. Alekseev belongs to a general range of the screw-propelled vehicles by its inertial energy parameters. Through its design features the developed rescue vehicle has sufficient buoyancy to remain afloat being fully loaded even in case of depressurization of the propellers (rotors). This in turn has a positive effect on durability of the rescue vehicle and on the success of the rescue operation.

The calculations showed that the universal rescue vehicle keeps a stable equilibrium state when maneuvering and has a smooth rocking in the process of stable movement. The universal rescue vehicle also has the ability to maintain the straightness of the movement and the smallest deviation from the course at the fixed position of the steering.

This work was performed in the NNSTU named after R. E. Alekseev supported by the Ministry of Education and Science RF under the Federal program "Research and development on priority directions of scientific-technological complex of Russia for 2014-2020". The unique identification number of the project: RFMEFI57714X0105.

\section{REFERENCES}

[1] Krasheninnikov M., Kulashov A., Shapkin V., Koshurina A. The concept and methodology of creating the universal life-saver with rotaryscrew mover // Lecture Notes in Electrical Engineering. - 2013. Volume 195 LNEE, Issue VOL. 7. - p. 477-490.

[2] I. O. Donato, V.A. Zhuk, B.V. Kuznetsov, A. P. Kulyashov, V.A. Shapkin, Y.V. Scherbakov. Rotary screw machines. Fundamentals of the theory of motion. N.Novgorod. 2000, p 451.

[3] M. Y. Alferev. The theory of the ship. M. River transport. 1959, p. 491.

[4] Y. I. Voytkunsky. Reference on the theory of the ship. Leningrad. Sudostroenie.1985, Vol 2, p. 440. R. Nicole, "Title of paper with only first word capitalized," J. Name Stand. Abbrev., in press.

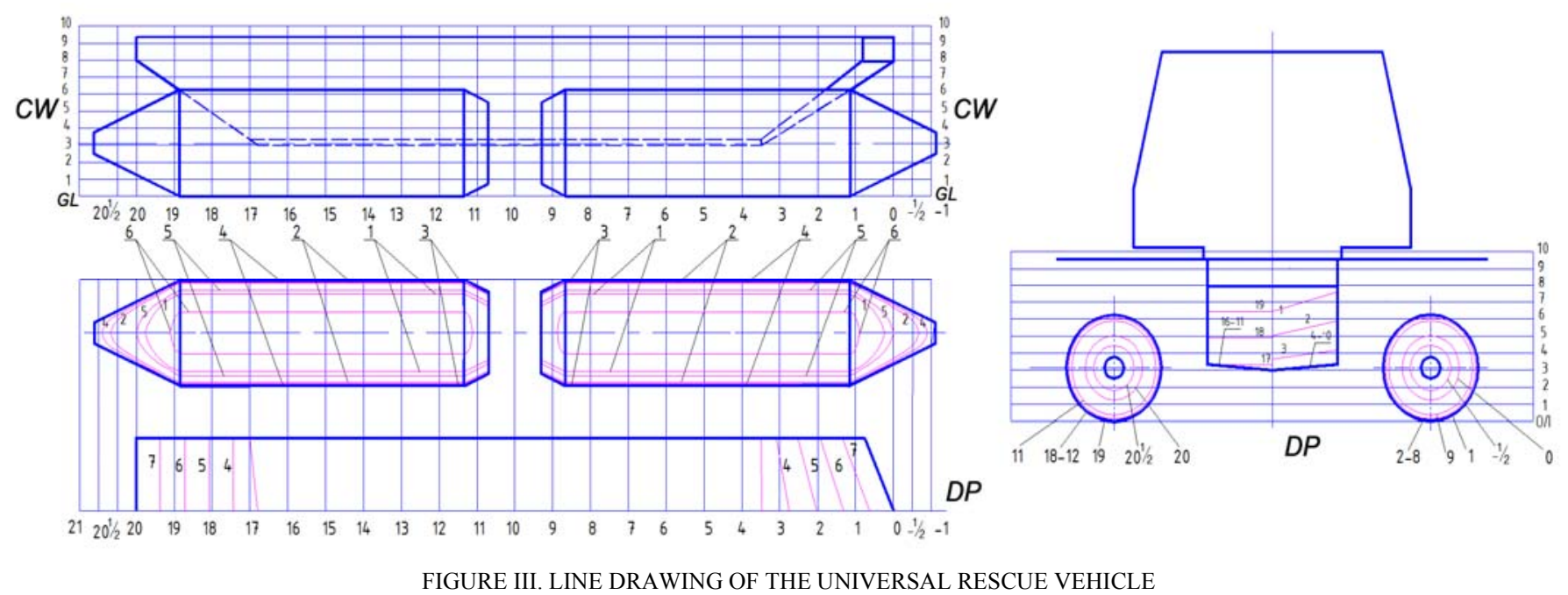

